\title{
Perceived Organizational Support, Job Satisfaction and Employee Performance: An Chinese Empirical Study
}

\author{
Rentao Miao ${ }^{1}$, Heung-Gil Kim² \\ ${ }^{1}$ School of Business Administration, University of Science \& Technology Liaoning, Anshan, China; ${ }^{2}$ Department of Business Ad- \\ ministration, Gyeongsang National University, Jinju, Korea. \\ Email:mrtmiao@hotmail.com,hgkim@gnu.ac.kr
}

Received December $15^{\text {th }}, 2009$; revised February $9^{\text {th }}, 2010$; accepted March $10^{\text {th }}, 2010$.

\begin{abstract}
The study investigated the generalizability of perceived organizational support and job satisfaction as positive correlations of employee performance in China. In a study conducted, 130 matched cases of 130 employees and their $34 \mathrm{im}-$ mediate supervisors from two large-scale state-owned enterprises (SOE) were selected as participants. Well-established psychological scales measuring perceived organizational support (POS), job satisfaction, and four facets of organizational citizenship behavior $(O C B)$ were administered. Data analyzed using zero-order correlation and hierarchical regression analysis showed positive correlations of POS and job satisfaction with work performance, and also showed independent and joint positive associations of POS and job satisfaction with $O C B$ and each of its four dimensions.
\end{abstract}

Keywords: Perceived Organizational Support, Job Satisfaction, Work Performance, Organizational Citizenship Behavior, China

\section{Introduction}

In recent decades, a major concern of organizational theorists and practitioners is organizational effectiveness. Quite essential for achieving this is the willingness of employees to go beyond the formal specifications of job roles, termed extra-role behaviors [1,2]. Among these behaviors, organizational citizenship behavior is the most widely studied form [3]. It has been defined as "individual behavior that is discretionary, not directly or explicitly recognized by the formal reward system and that in aggregate promotes the effective functioning of the organization" (Organ 1988, p.4). Only a few studies have examined organizational citizenship behavior in different cultural contexts [4-7]. Nonetheless, researchers have found that the motivational basis of organizational citizenship behavior differs in the West and China [5,7]. From a Chinese perspective, OCB is not simply a consequence of job satisfaction or organizational commitment [8], but rather a kind of service that is typically attributed to personal loyalty and attachment to specific others rather than as an impersonal form of commitment [4].

This work was supported by the University of Science \& Technology Liaoning, P. R. China.
Because [9] suggested that China is a relational society, in that a strong relationship may be sufficient for inducing employee reciprocity. Personal relationships, particularly between subordinates with immediate supervisors, therefore may play a larger role in motivating organizational citizenship behavior and performance in China than they do in the West. Therefore, there is a need for providing insights on some of the predictions of expatriates' work attitudes and outcomes in the Chinese context [10].

To verify the contentions of Chinese academics about Chinese workers, that low structural stability results from transitional societies and economic changes, especially the reform of state-owned enterprises, some hypotheses are drawn along the combinations of the Chinese and western literature. The purpose of this study was to examine the relationships between perceived organizational supports, job satisfaction and employee performance in China. This replication was needed so that previous findings could be generalized beyond the United States. First, we examined the extent to which job satisfaction is associated with OCB and in-role performance. Second, we investigated the relationships between perceived organizational support and OCB and in-role performance. 


\section{Theoretical Background}

\subsection{Employee Performance}

Unlike many Western countries, the concept of employee performance (called Biaoxian) in the PRC goes beyond the actual work of the employees and includes many non-work related aspects. So employee performance has been classified into two dimensions [11,12], such as: work performance and OCB. Work performance is one of the most important concerns for any organization and has received much attention [13], and it is typically viewed as fundamental or in-role responsibilities that employees are hired to perform in exchange for their compensation packages [14].

OCB is constructive behavior, not included in an employee's formal job description. Research on OCB has benefited greatly from Organ's (1988) conceptualization of OCB as consists of five distinct factors of altruism (e.g., helping behaviors directed at specific individuals), courtesy (e.g., informing others to prevent the occurrence of work-related problems), sportsmanship (e.g., tolerating the inevitable inconveniences of work without complaining), conscien-tiousness (e.g., going beyond minimally required levels of attendance), and civic virtue (e.g., participating in and being concerned about the life of the company). Reference [15] first operationalized Organ's five-dimension model of OCB. More recent conceptualizations of OCB offer slightly different categorizations. For example, [16] combined aspects of altruism and courtesy termed it helping. Reference [17] found support for a three-factor model of OCB. In this conceptualization, conscientiousness is removed and altruism and courtesy are combined with cheerleading to form a single helping dimension, resulting in three factors (i.e., helping behavior, civic virtue, and sportsmanship). And in a thorough review of the OCB literature and other related constructs, [12] proposed seven themes according to the type of behavior: helping behaviors, sportsmanship, organizational loyalty, organizational compliance, individual initiative, civic virtue, and self-development.

Reference [5] developed a version of the OCB measure for the Chinese culture and translated it into the Mandarin language. The Chinese version included the dimensions of altruism, conscientiousness, and civic virtue, but replaced sportsmanship and courtesy with two dimensions of interpersonal harmony and protecting company resources more closely related to the Chinese culture. Reference [6] proposed a concentric model to classify OCB in China, and divided them into four domains based on the focus or context of action: self-contributions that in principle could be rendered anonymously, privately, and purely as a matter of one's own volition, such as self-training, taking initiative, and keeping the workplace clean; group-contributions that cannot be meaningfully or practically divorced from a context of interaction with peers, such as interpersonal harmony and helping coworkers; organization-contributions that must engage some organizationally relevant attribute, such as protecting and saving company resources, voice and group activity participation; and society-contributions that can be enacted only across the boundary of the organization or in its external environment with outside stakeholders, such as social welfare participation and protecting company image.

In the present study, we examine a wide array of antecedent variables for their potential effect on OCB, which is comprised of the following behaviors: (a) Helping behaviors, (b) Courtesy, (c) Conscientiousness, and (d) Civic virtue.

\subsection{Antecedents of Employee Performance}

Given the interest and apparent utility to organizations regarding organizational citizenship and work performance, it is useful to identify the antecedents of such performance. Perceptions of leader supportiveness and follower job satisfaction have been found to be positively related to behavior [18].

Perceived organizational support refers to "the extent to which the organization values [employees'] contributions and cares about their well-being" [19]. A supportive organization is committed to its workers [20]. According to organizational support theorists, high POS tends to improve work attitudes and engender effective work behavior for two reasons. First, these beneficial effects result from a process of social exchange. Research by [21] suggests that workers examine the discretionary actions of discretion to have done, otherwise, and then workers infer that they are being supported. They then seek to repay this favorable treatment. Like that, employees become more committed and harder-working [19]. In addition, it seems that if an organization is given adequate training, resources, and support from management, it is more likely that members would both want their organization to succeed and be more capable of helping their organization succeed. Therefore, it appears likely that the extent which the organization perceives that it is supported will be positively associated with the display of OCB directed toward the organization $[22,23]$. Thus, we hypothesize that the extent to which an organization perceives that management provides it with support will affect the citizenship behaviors:

Hypothesis 1: Perceived organizational support will independently and jointly be positively associated with OCB. These include (a) helping behaviors, (b) courtesy, (c) conscientiousness, and (d) civic virtue.

An important component of this study is to examine the source of the support associated with work performance. The same as mentioned above, research on social exchange theory has shown that employees who feel they receive high levels of support from their organizations 
are more likely to perform better than those who do not [24]. On the other hand, [25] and [26] tested the relationship between POS and work performance using structural equation modeling. In both of these studies the path coefficient from POS and work performance was not significant. However, [27] reported a modest relationship between POS and work performance. We reason that the existence of collectivism in Chinese context may have a significant influence on the dynamic that links support in the workplace with performance. Because [5] suggested that collectivist cultures have stronger bonds within a larger in-group, where helping behavior occurs for the good of the group. [28] suggested that collectivist cultures would demonstrate more work behavior. Thus, we hypothesize POS will be related positively to performance that:

Hypothesis 2: Perceived organizational support will be positively associated with work performance.

Job satisfaction refers to an employee's overall sense of well-being at work. It is an internal state based on assessing the job and job-related experiences with some degree of favor or disfavor [29]. There is substantial support for the relationship between job satisfaction and OCB. Reference [11] and [30] has argued for and provided empirical evidence supporting a relationship between satisfaction and OCB, as did [31]. [32] found support for the relative importance of cognitive job satisfaction over affective job satisfaction in predicting OCB. Reference [33] found that overall job satisfaction yielded a significant increment in the altruism dimension of OCB, but not in the compliance dimension of OCB. In a sample of human-service professionals, [34] found that job satisfaction is positively correlated with OCB to a degree that indicates a medium to strong relationship. Therefore, consistent with the results of prior research, we hypothesize that:

Hypothesis 3: Job satisfaction will independently and jointly be positively associated with OCB. These include (a) helping behaviors, (b) courtesy, (c) conscientiousness, and (d) civic virtue.

Since the 1970 s job satisfaction is often conceptualized as a determinant of general work performance although the empirical relationship is of weak to moderate strength with meta-analytic estimates of the relationship ranging from 0.18 [35] to 0.30 [36]. References [13] and [29] also showed no strong relationship between these two variables. The relative weakness of this relationship may be due to the fact that much of this research has adopted an overly narrow view of work performance by focusing primarily on the task performance subset of the work performance space. Thus, the satisfaction-performance research has still failed to produce strong and unambiguous findings. This necessitates further investigation of relationship between these two variables. Based on the previous literature, we hypothesize that:
Hypothesis 4: Job satisfaction will be positively associated with work performance.

\section{Methods}

\subsection{Sample}

Initially, employees were systematically selected from various departments in Chinese steel corporations-Anshan Iron \& Steel Corporation and Benxi Iron \& Steel Corporation, and then we distributed 159 pairs of questionnaires to these employees and their 34 immediate supervisors and collected, among which 29 pairs contained multiple missing items and were thus excluded, only 130 matched cases of supervisor-subordinate dyads $(81.8 \%)$ were obtained. An average age of the participants was 36.79 years $(S D=13.08) ; 61.8 \%$ were male and $38.2 \%$ were female. Their average of tenure in their respective departments was 9.05 years.

\subsection{Procedure}

We used two questionnaires: one for the subordinate employees and the other for their immediate supervisors. The subordinate questionnaire measured perceived organizational support, job satisfaction, along with control variables. The supervisor questionnaire assessed each subordinate's job performance and organizational citizenship behavior. Questionnaires were sent to potential respondents by the company internal e-mail system with the help of our friends. We asked the respondents to send the completed questionnaires directly to the researcher by e-mail. We explained to the respondents that the identification number on the survey was for data matching purpose only. Participant responses were anonymous to the researchers and responses from individual employees were kept confidential from management.

\subsection{Measures}

Unless otherwise noted, all of the scales described below were responded to on a five-point Likert type scale $(1=$ strong disagreement, 5 = strong agreement).

Control Variables. Past research has demonstrated that gender, age, and organizational tenure can influence Chinese employee work perceptions (POS), attitudes, and behaviors [37,38], and so I included these as controls in my analysis: gender $(0=$ female, $1=$ male), age (four ordered categories), and tenure (years).

Perceived Organizational Support. We measured perceived organizational support with 4-item (Cronbach's alpha $=0.89$ ) taking from [19] to assess how well the organization thought that management supported it. Example items are 'The organization does its best to take care of different needs of colleagues', and 'The organization appreciates the contribution of every colleague.'

Job Satisfaction. We measured job satisfaction with 5 -item $(\alpha=0.80)$ using the short form of [39] job satis- 
faction questionnaire. This scale consisted of the following facets: job interest, feedback from agents, co-workers, fair treatment, and supervision.

Employee Performance. It was operationalized as the performance of the members on their assigned tasks, and as OCB of the members' extra-role performance.

Work Performance. We measured work performance by 3 -item $(\alpha=0.69)$ based on prior measures [40,41], such as 'This employee almost always perform better than what can be characterized as acceptable performance', and 'This employee often perform better than what can be expected.'

$O C B$. We measured OCB by an adaptation of the scale developed by [11] and [6]. Four dimensions of OCB $(\alpha=$ 0.86) were used in the present study: 1) Helping behaviors-discretionary behaviors that have the effect of helping a specific other person with work-related matters as well as nonwork matters, it's broader in scope of China than its Western counter-parts $(\alpha=0.81)$; 2) Courtesy-discretionary behaviors aimed at preventing workrelated problems from occurring ( $\alpha=0.73)$; 3) Conscientiousness-discretionary behaviors on the part of the employee in the areas of attendance, obeying rules and regulations, taking breaks, and so forth $(\alpha=0.75)$; and 4) Civic virtue-behavior on the part of individuals indicating that they responsibly participate in, are involved in, or are concerned about the life of the organization $(\alpha=$ 0.71). Sample items are: Helping behaviors 'willing gives of his/her time to help others who have work-related problems'; Courtesy 'tries to avoid creating problems for co-workers'; Conscientiousness 'always punctual at work'; Civic virtue 'attend formal and informal organization meetings.'

\section{Results}

Before testing our hypotheses, principal factor analyses were performed on the items to which the subordinates and their immediate supervisors responded. Seven factors emerged with eigenvalues greater than 1.0, explaining $64.60 \%$ of the variance.

Supervisors responded to a total 15 -item measuring OCB (helping behaviors, courtesy, conscientiousness, and civic virtue) and work performance. Subordinates responded to a total 9-item measuring POS and job satisfaction.

Table 1 shows the mean, standard deviations, zeroorder correlations, and reliability coefficients of the study variables. Zero-order correlations provide an initial examination of the hypotheses linking POS, job satisfaction, and OCBs, work performance (Table 1). The hypothesis stating positive relationship between POS and OCB is supported $(r=0.50, p<0.001)$. POS was also correlated positively with helping behaviors $(r=0.39, p<0.001)$, courtesy $(r=0.30, p<0.001)$, conscientiousness $(r=$ $0.23, p<0.01)$, and civic virtue $(r=0.42, p<0.001)$. Positive correlation was also obtained between job satisfaction and OCB $(r=0.34, p<0.001)$, helping behavior $(r=0.20, p<0.05)$, courtesy $(r=0.16, p>0.05)$, conscientiousness $(r=0.31, p<0.001)$, and civic virtue $(r=$ $0.22, p<0.05)$. In addition, consistent with hypothesis 2 , POS also correlated positively with work performance $(r$ $=0.20, p<0.05)$, and consistent with hypothesis 4 , job satisfaction correlated positively with work performance $(r=0.34, p<0.001)$. It appears that POS and job satisfaction had differential effects on OCB and work performance.

Table 1. Mean, standard deviations and zero-order correlations

\begin{tabular}{|c|c|c|c|c|c|c|c|c|c|c|c|c|c|}
\hline Variables & Mean & $S D$ & 1 & 2 & 3 & 4 & 5 & 6 & 7 & 8 & 9 & 10 & 11 \\
\hline 1. POS & 3.68 & 0.72 & $(0.89)$ & & & & & & & & & & \\
\hline 2. JS & 4.02 & 0.47 & $0.18^{*}$ & $(0.80)$ & & & & & & & & & \\
\hline 3. OCB & 3.84 & 0.40 & $0.50 * * *$ & $0.34 * * *$ & $(0.86)$ & & & & & & & & \\
\hline 4. HB & 3.99 & 0.56 & $0.39 * * *$ & 0.20 * & $0.64 * * *$ & $(0.81)$ & & & & & & & \\
\hline 5. Courtesy & 3.81 & 0.64 & $0.30 * * *$ & 0.16 & $0.68 * * *$ & $0.37 * * *$ & $(0.73)$ & & & & & & \\
\hline 6. Consci & 3.47 & 0.75 & $0.23 * *$ & $0.31 * * *$ & $0.62 * * *$ & $0.43 * * *$ & $0.34 * * *$ & $(0.75)$ & & & & & \\
\hline 7. CV & 4.09 & 0.51 & $0.42 * * *$ & $0.22 *$ & $0.64 * * *$ & $0.35^{* * *}$ & $0.26^{* *}$ & $0.19 *$ & $(0.71)$ & & & & \\
\hline 8. WP & 3.59 & 0.59 & $0.20^{*}$ & $0.34 * * *$ & $0.28 * *$ & 0.14 & 0.17 & $0.18 *$ & $0.24 * *$ & $(0.69)$ & & & \\
\hline 9. Gender & 1.40 & 0.51 & -0.14 & -0.13 & -0.12 & -0.11 & 0.04 & -0.08 & $-0.18^{*}$ & $-0.23 * *$ & - & & \\
\hline 10. Age & 36.79 & 13.08 & $-0.24 * *$ & -0.08 & $-0.23^{* *}$ & -0.14 & $-0.25^{* *}$ & -0.13 & -0.05 & -0.16 & -0.10 & - & \\
\hline 11. Tenure & 9.05 & 3.40 & $-0.18^{*}$ & $0.18^{*}$ & -0.13 & 0.05 & $-0.17^{*}$ & -0.02 & $-0.20 *$ & -0.02 & -0.10 & $0.35 * * *$ & - \\
\hline
\end{tabular}

Notes: $* \mathrm{P}<0.05 ; * * \mathrm{P}<0.01 ; * * \mathrm{P}<0.001$. Cronbach's alphas for applicable scales are shown on the diagonal.

POS: perceived organizational support; JS: job satisfaction; OCB: organizational citizenship behavior; HB: helping behaviors; Consci: conscientiousness; CV: civic virtue; WP: work performance. 
To test the hypotheses more thoroughly, we used hierarchical multiple regression. In step 1, we entered the demographic variables of gender, age, and tenure for control; and in step 2, we entered perceived organizational support and job satisfaction. Results of the hierarchical regressions are shown in Table 2. The control variables jointly accounted for $9 \%$ of the variance in OCB, $F(4,126)=3.13, p<0.05$, with only gender $(\beta=$ $-0.18, p<0.05)$ and age $(\beta=-0.23, p<0.01)$ contributing significantly. But the inclusion of the antecedents (POS and job satisfaction) resulted in $35 \%$ variation in OCB, $F(6,124)=11.09, p<0.001$, with only POS $(\beta=$ $0.42, p<0.001)$ and job satisfaction $(\beta=0.27, p<0.01)$ contributing significantly. The inclusion of the antecedents resulted in $26 \%$ change $\left(\Delta R^{2}\right)$ in variance in OCB. For helping behavior, the $5 \%$ variance accounted by the control variables was not significant but the inclusion of the antecedents resulted significant $19 \%$ variance, $F(6,124)=4.71, p<0.001$; only POS $(\beta=0.37, p<$ $0.001)$ and job satisfaction $(\beta=0.19, p<0.05)$ contributed significantly. On courtesy, the control variables accounted for $8 \%$ variance, $F(4,126)=2.77, p<0.05$; with only age $(\beta=-0.22, p<0.05)$ contributing significantly. The inclusion of the antecedents yielded $15 \%$ variation $\left(\Delta R^{2}=7 \%\right), F(6,124)=3.67, p<0.01$, with only POS $(\beta$ $=0.23, p<0.01)$ contributing significantly. For conscientiousness, the $4 \%$ variance accounted by the control variables was not significant but the inclusion of the antecedents resulted significant $15 \%$ variance, $F(6,124)=$ $3.71, p<0.01$; only POS $(\beta=0.18, p<0.05)$ and job satisfaction $(\beta=0.27, p<0.01)$ contributed significantly. Finally, the inclusion of the control variables in the regression on civic virtue yielded $8 \%$ variance, $F(4,126)=$ $2.86, p<0.05$; with only gender $(\beta=-0.19, p<0.05)$ and tenure $(\beta=-0.22, p<0.05)$ contributing significantly. The inclusion of the antecedents yielded $26 \%$ variance $\left(\Delta R^{2}=18 \%\right), F(6,124)=7.31, p<0.001$, with only $\operatorname{POS}(\beta=0.36, p<0.001)$ and job satisfaction $(\beta=$ $0.21, p<0.05)$ contributing significantly. The joint association of POS with OCB and its dimensions were correlated significantly. Thus, Hypotheses 1(a), 1(b), 1(c) and 1(d) were supported. Hypotheses 1 was supported. However, despite no relationship between job satisfaction and courtesy, the joint association of job satisfaction with OCB was correlated significantly. Thus, Hypotheses 3(a), 3(c) and 3(d) were supported, while 3(b) was not. Hypotheses 3 was partial supported.

The control variables accounted for $8 \%$ of the variance in work performance, $F(4,126)=2.83, p<0.05$, with only gender $(\beta=-0.23, p<0.01)$ and age $(\beta=-0.19, p<$ $0.05)$ contributing significantly. But the inclusion of the antecedents (POS and job satisfaction) resulted in $19 \%$ variation in work performance, $F(6,124)=4.70, p<0.01$, with only $\operatorname{POS}(\beta=0.18, p<0.05)$, job satisfaction $(\beta=$ $0.31, p<0.001)$ and gender $(\beta=-0.19, p<0.05)$ contributing significantly. The inclusion of the antecedents resulted in $11 \%$ change $\left(\Delta R^{2}\right)$ in variance in work performance. The associations of POS and job satisfaction with work performance were correlated significantly. Thus, Hypotheses 2 and 4 were supported.

Table 2. Hierarchical regression analysis predicting the effectss of POS and job satisfaction on employee performance

\begin{tabular}{|c|c|c|c|c|c|c|c|c|c|c|c|c|}
\hline \multirow[b]{2}{*}{ Variables } & \multicolumn{2}{|c|}{ Helping behaviors } & \multicolumn{2}{|c|}{ Courtesy } & \multicolumn{2}{|c|}{ Conscientiousness } & \multicolumn{2}{|c|}{ Civic virtue } & \multicolumn{2}{|c|}{$O C B$} & \multicolumn{2}{|c|}{ Workperformance } \\
\hline & $M 1$ & $M 2$ & $M 1$ & $M 2$ & $M 1$ & $M 2$ & $M 1$ & $M 2$ & $M 1$ & $M 2$ & $M 1$ & $M 2$ \\
\hline & $\beta$ & $\beta$ & $\beta$ & $\beta$ & $\beta$ & $\beta$ & $\beta$ & $\beta$ & $\beta$ & $\beta$ & $\beta$ & $\beta$ \\
\hline \multicolumn{13}{|l|}{ 1.Controls } \\
\hline Gender & -0.14 & -0.07 & -0.07 & -0.02 & -0.08 & -0.03 & $-0.19^{*}$ & -0.11 & $-0.18^{*}$ & -0.08 & $-0.23 * *$ & $-0.19 *$ \\
\hline Age & $-0.19 *$ & -0.10 & $-0.22 *$ & -0.15 & -0.15 & -0.07 & 0.01 & 0.12 & $-0.23 * *$ & -0.09 & $-0.19 *$ & -0.12 \\
\hline Tenure & 0.09 & 0.12 & -0.11 & -0.11 & 0.01 & -0.03 & $-0.22 *$ & $-0.22 *$ & -0.08 & -0.09 & 0.01 & -0.09 \\
\hline \multicolumn{13}{|l|}{$\begin{array}{l}\text { 2.Antece- } \\
\text { dent }\end{array}$} \\
\hline POS & & $0.37 * * *$ & & $0.23^{* *}$ & & $0.18 *$ & & $0.36^{* * * *}$ & & $0.42^{* * *}$ & & $0.18 *$ \\
\hline $\mathbf{J S}$ & & $0.19 *$ & & 0.12 & & $0.27^{* *}$ & & $0.21 *$ & & $0.27 * *$ & & $0.31 * * *$ \\
\hline$R^{2}$ & 0.05 & $0.19^{* * *}$ & $0.08^{*}$ & $0.15^{* *}$ & 0.04 & $0.15^{* *}$ & $0.08^{*}$ & $0.26^{* * *}$ & $0.09 *$ & $0.35 * * *$ & $0.08^{*}$ & $0.19^{* *}$ \\
\hline $\operatorname{Adj}-R^{2}$ & 0.02 & $0.15^{* * *}$ & $0.05^{*}$ & $0.11 * *$ & 0.01 & $0.11^{* *}$ & $0.05^{*}$ & $0.23 * * *$ & $0.06^{*}$ & $0.32 * * *$ & $0.05^{*}$ & $0.15^{* *}$ \\
\hline$F$ & 1.67 & $4.71 * * *$ & $2.77^{*}$ & $3.67 * *$ & 1.40 & $3.71 * *$ & $2.86^{*}$ & $7.31 * * *$ & $3.13 *$ & $11.09 * * *$ & $2.83^{*}$ & $4.70^{* *}$ \\
\hline$\Delta R^{2}$ & & $0.14 * * *$ & & $0.07^{* *}$ & & $0.11 * *$ & & $0.18^{* * *}$ & & $0.26^{* * *}$ & & $0.11^{* *}$ \\
\hline$d f$ & $4 / 126$ & $6 / 124$ & $4 / 126$ & $6 / 124$ & $4 / 126$ & $6 / 124$ & $4 / 126$ & $6 / 124$ & $4 / 126$ & $6 / 124$ & $4 / 126$ & $4 / 124$ \\
\hline
\end{tabular}

Notes: $* \mathrm{P}<0.05 ; * * \mathrm{P}<0.01 ; * * * \mathrm{P}<0.001$. POS: perceived organizational support; JS: job satisfaction; OCB: organizational citizenship behavior. 


\section{Discussion}

Factor analysis supported the existence of four separate factors representing the POS, job satisfaction, OCB, and work performance. Among them employee performance consist of OCB (extra-role behaviors) and work performance (in-role behaviors) in this study. Prior studies $[22,23]$ and $[25,26]$ suggested the relationships between POS and OCB, POS and work performance are significant respectively. And prior studies [11,30] and $[35,36]$ found job satisfaction has significant effect on OCB and work performance respectively. According to the principle of compatibility, we expect that, for Chinese workers, perceived organizational support relates to organizational citizenship behavior and work performance (Hypothesis 1,2). Furthermore, job satisfaction also relates to organizational citizenship behavior and work performance (Hypothesis 3, 4).

Interestingly, this principle generalizes to the effects of both perceived organizational support and job satisfaction. That is to say, findings from the present study support existing findings in the Western literature that OCBs and work performance increase with more favorable perception of organizational support and job satisfaction. The Chinese respond to job satisfaction in a manner similar to Westerners. There is no difference about the effects of job satisfaction on performance between Chinese and Westerners. That is to say, they become more committed to the organization and hard-working. However, they respond to organizational support more strongly than do Westerners, with greater citizenship behavior and work performance. It is different from prior western studies [25-27] report mixed findings with regards to the relationship between POS and work performance. The importance of personal relationship (called Guanxi) in Chinese business dealings has been well documented $[42,43]$. The salience of interpersonal relationship in Chinese daily life suggests POS in Chinese cultural context improve work performance more strongly than do in Western context. This study offers additional insight into the support-performance relationship in China.

Both organizational citizenship behavior and work performance can be construed as a form of reciprocity to a specific person. By the empathy concern behavior hypothesis an employee who perceives favorable organizational support and job satisfaction at workplace, shows empathic concern for the organization by engaging in citizenship behaviors. The norm of reciprocity also posits that people who give should be paid back. Employees evaluate their work situations by cognitively in return. Thus, employees empathize and reciprocate organizational support and job satisfaction with work behaviors (extra-role behaviors and in-role behaviors). This is because study [44] suggested that people are most satisfied with a relationship when the ratio between benefits and contributions is similar for both partners; and also studies $[45,46]$ showed that OCB is positively related to work performance. Worker's relationship with a supervisor takes on paramount importance to Chinese employees and is an essential component of Chinese social structure. The relationship with one's supervisor, therefore, may anchor the relationship with the organization and one's willingness to contribute to it.

In addition, interestingly, an important finding from the present study is contrary to the existing findings in the Western literature that the satisfaction-work perfor mance relationship does significantly exceed the satisfaction-OCB relationship [47]. In other words, Chinese employees with more job satisfaction may promote employees to show more citizenship behaviors, while more job satisfaction can not improve job performance relatively.

The findings reported may have some interesting implications for managers. First, organizational support is important for enhancing employee performance, making employees' perceptions of organizational support an area that managers cannot ignore. For the Chinese workforce to drive towards employee performance, management of organizations need to enhance organizational support by implementing organization policies, attitudes, procedures, and decisions that support and value employees' contributions, and cares about their well-being. In addition, job satisfaction can also enhance employee performance. So how to make employees to satisfy their work lives? By aiming at improving employee job satisfaction thus managers need to simultaneously address as many of diverse variables (e.g., provide employee well-deserved gains, resolve their concerns, job enrichment and reduction in workplace discrimination) as possible in order to ensure performance.

\subsection{Limitations}

Limitations to this study include it cross-sectional design that precludes us from drawing conclusions concerning the causal relationships among the study variables. In addition, the sample was small, compared to other studies on citizenship behavior; thus our power for detecting between several relationships effects was relatively low. Finally, our sample was limited to the heavy industry of two large-scale state-owned enterprises which may limit the generalizability of the results.

\subsection{Future Research}

Under circumstances of China's transformation, Chinese workers appear to be increasingly attracted to joining foreign rather than SOE. Therefore, we must raise the question of how workers in SOE conglomerates compare with workers in foreign firms. Future research should examine the foreign-invested enterprises and sino-foreign joint ventures with the reform and modernization. On the other hand, it would be of value to examine further vari- 
ables (e.g., organizational justice, commitment, interpersonal trust, and psychological contract) of antecedents, broaden the domain of outcomes to include more objective data.

\section{REFERENCES}

[1] D. W. Organ, "The Motivational Basis of Organziational Citizenship Behavior," JAI Press, Greenwich, CT, 1990.

[2] B. J. Tepper, D. Lockhart and J. Hoobler, "Justice, Citizenship, and Role Definition Effects," Journal of Applied Psychology, Vol. 86, No. 4, 2001, pp. 789-796.

[3] V. Dyne, L. L. Cummings and J. M. Parks, "Extra-Role Behaviors: In Pursuit of a Construct and Definitional Clarity (a Bridge over Mudded Waters)," JAI Press, Greenwich, CT, 1995.

[4] Z. X. Chen, A. S. Tsui and J. L. Farh, "Loyalty to Supervisor Versus Organizational Commitment: Relationships to Employee Performance in China," Journal of Occupational Organization, Vol. 75, 2002, pp. 339-356.

[5] J. L. Farh, S. C. Earley and S. C. Lin, "Impetus for Action: A Cultural Analysis of Justice and Organizational Citizenship Behavior in Chinese Society," Administrative Science Quarterly, Vol. 42, No. 3, 1997, pp. 421-444.

[6] J. L. Farh, C. B. Zhong and D. W. Organ, "Organizational Citizenship Behavior in the People's Republic of China," Organization Science, Vol. 15, No. 2, 2004, pp. 241-253.

[7] C. Hui, K. S. Law and Z. X. Chen, "A Structural Equation Model of the Effects of Negative Affectivity, LeaderMember Exchange, and Perceived Job Mobility on InRole and Extra-Role Performance: A Chinese Case," Organizational Behavior and Human Decision Processes, Vol. 77, No. 1, 1999, pp. 3-21.

[8] D. W. Organ and K. Ryan, "A Meta-Analytic Review of Attitudinal and Dispositional Predictors of Organizational Citizenship Behavior," Personnel Psychology, Vol. 48, No. 4, 1995, pp. 775-802.

[9] C. Hui, C. Lee and D. M. Rousseau, "Employment Relationships in China: Do Workers Relate to the Organization or the People?" Organization Science, Vol. 15, No. 2, 2004, pp. 232-240.

[10] Y. W. Liu, "Perceived Organizational Support and Expatriate Organizational Citizenship Behavior," Personnel Review, Vol. 38, No. 3, 2009, pp. 307-319.

[11] D. W. Organ, "Organizational Citizenship Behavior: The Good Soldier Syndrome," Lexington Books, Lexington, MA, 1988.

[12] P. M. Podsakoff, S. B. MacKenzie, J. B. Paine and D. G. Bachrach, "Organizational Citizenship Behaviors: A Critical Review of the Theoretical and Empirical Literature and Suggestions for Future Research," Journal of Management, Vol. 26, No. 3, 2000, pp. 513-563.

[13] S. P. Brown and R. A. Peterson, "Antecedents and Consequences of Salesperson Job Satisfaction: A Metaanalysis and Assessment of Causal Effects," Journal of Marketing, Vol. 30, No. 1, 1993, pp. 63-77.
[14] D. M. Rousseau and J. McLean Parks, "The Contracts of Individuals and Organizations (Research in Organizational Behavior," JAI Press, Greenwich, CT, 1993.

[15] P. M. Podsakoff, S. B. macKenzie, R. H. Moorman and R. Fetter, "Transformational Leader Behaviors and their Effects on Followers' Trust in Leader, Satisfaction, and Organizational Citizenship Behaviors," Leadership Quarterly, Vol. 1, No. 2, 1990, pp. 107-142.

[16] P. M. Podsakoff and S. B. MacKenzie, "Organizational Citizenship Behaviors and Sales Unit Effectiveness," Journal of Marketing Research, Vol. 31, No. 3, 1994, pp. 351-363.

[17] P. M. Podsakoff, M. Ahearne and S. B. MacKenzie, "Organizational Citizenship Behavior and the Quantity and Quality of Work Group Performance," Journal of Applied Psychology, Vol. 82, No. 2, 1997, pp. 262-270.

[18] C. A. Smith, D. W. Organ and J. P. Near, "Organizational Citizenship Behavior: its Nature and Antecedents," Journal of Applied Psychology, Vol. 68, No. 4, 1983, pp. 653-663.

[19] R. Eisenberger, R. Huntington, S. Hutchison and D. Sowa, "Perceived Organizational Support," Journal of Applied Psychology, Vol. 71, No. 3, 1986, pp. 500-507.

[20] R. M. Malatesta and L. E. Tetrick, "Understanding the Dynamics of Organizational and Supervisory Commitment," Presented at the Annual Meeting of the Society for Industrial and Organizational Society, San Diego, CA, 1996.

[21] R. Eisenberger, J. Cummings, S. Armeli and P. Lynch, "Perceived Organizational Support, Discretionary Treatment, and Job Satisfaction," Journal of Applied Psychology, Vol. 82, No. 5, 1997, pp. 812-820.

[22] R. Eisenberger, S. Armeli, B. Rexwinkel, P. D. Lynch and L. Rhoades, "Reciprocation of Perceived Organizational Support," Journal of Applied Psychology, Vol. 86, No. 1, 2001, pp. 42-51.

[23] S. J. Wayne, L. M. Shore, W. H. Bommer and L. E. Tetrick, "The Role of Fair Treatment and Rewards in Perceptions of Organizational Support Member Exchange," Journal of Applied Psychology, Vol. 87, No. 3, 2002, pp. 590-598.

[24] R. Eisenberger, P. Fasolo and V. Davis-LaMastro, "Perceived Organizational Support and Employee Diligence, Commitment, and Innovation," Journal of Applied Psychology, Vol. 75, No. 1, 1990, pp. 51-59.

[25] R. P. Settoon, N. Bennett and R. C. Liden, "Social Exchange in Organizations: Perceived Organizational Support, Leader-Member Exchange, and Employee Reciprocity," Journal of Applied Psychology, Vol. 81, No. 3, 1996, pp. 219-227.

[26] S. J. Wayne, L. M. Shore and R. C. Liden, "Perceived Organizational Support and Leader-Member Exchange: A Social Exchange Perspective," Academy of Management Journal, Vol. 40, No. 1, 1997, pp. 82-111.

[27] Z. S. Byrne and W. A. Hochwarter, "Perceived Organizational Support and Performance: Relationships across Levels of Organizational Cynicism," Journal of Mana- 
gerial Psychology, Vol. 23, No. 1, 2008, pp. 54-72.

[28] J. B. Paine and D. W. Organ, "The Cultural Matrix of Organizational Citizenship Behavior: Some Preliminary Conceptual and Empirical Observations," Human Resource Management Review, Vol. 10, No. 1, 2000, pp. 45-59.

[29] E. A. Locke, "The Nature and Cause of Job Satisfaction," Rand McNally, Chicago, IL, 1976.

[30] D. W. Organ and M. Konovsky, "Cognitive Versus Affective Determinants of Organizational Citizenship Behavior," Journal of Applied Psychology, Vol. 74, No. 1, 1989 , pp. 157-164.

[31] L. J. Williams and S. E. Anderson, "Job Satisfaction and Organizational Commitment as Predictors of Organizational Citizenship and In-Role Behaviors," Journal of Management, Vol. 17, No. 3, 1991, pp. 601-617.

[32] R. H. Moorman, "The Influence of Cognitive and Affective Based Job Satisfaction on the Relationship between Satisfaction and Organization Citizenship Behavior," Human Relations, Vol. 46, No. 6, 1993, pp. 759-776.

[33] D. W. Organ and A. Lingl, "Personality, Satisfaction, and Organizational Citizenship Behavior," Journal of Social Psychology, Vol. 135, No. 3, 1995, pp. 339-350.

[34] G. Murphy, J. Athanasou and N. King, "Job Satisfaction and Organizational Citizenship Behavior: A Study of Australian Human-Service Professionals," Jounal of Managerial Psychology, Vol. 17, No. 4, 2002, pp. 287-297.

[35] M. T. Iaffaldano and P. M. Muchinsky, "Job Satisfaction and Job Performance: A Meta-Analysis," Psychological Bulletin, Vol. 97, No. 2, 1985, pp. 251-273.

[36] T. A. Judge, C. J. Thoresen, J. E. Bono and G. K. Patton, "The Job Satisfaction-Job Performance Relationship: A Qualitative and Quantitative Review," Psychological Bulletin, Vol. 127, No. 3, 2001, pp. 376-407.

[37] C. H. Hui and C. K. Tan, "Employee Motivation and Attitudes in the Chinese Workforce,". In: M. H. Bond Ed., Handbook of Chinese psychology, Oxford University Press, New York, 1996, pp. 364-378.

[38] E. W. Morrison, "Role Definitions and Organizational
Citizenship Behavior: The Importance of Employee's Perspective," Academy of Management, Vol. 37, No. 6, 1994, pp. 1543-1567.

[39] E. S. Mason, "Gender Differences in Job Satisfaction," Journal of Social Psychology, Vol. 135, No. 2, 1995, pp. 143-151.

[40] J. Brockner, T. R. Tyler and R. Cooper-Schneider, "The Influence of Prior Commitment to an Institution on Reactions to Perceived Fairness: The Higher they Are, the Harder they Fall," Administrative Science Quarterly, Vol. 37, No. 2, 1992, pp. 241-261.

[41] T. Y. May, M. Korczynski and S. J. Frenkel, "Organizational and Occupational Commitment: Knowledge Workers in Large Corporations," Journal of Management Studies, Vol. 39, No. 6, 2002, pp. 775-801.

[42] J. L. Farh, A. S. Tsui, K. Xin and B. S. Cheng, "The Influene of Relational Demography and Guanxi: The Chinese Case," Organization Science, Vol. 9, No. 4, 1998, pp. 471-488.

[43] A. S. Tsui and J. L. Farh, "Where Guanxi Matters: Relational Demography and Guanxi in the Chinese Context," Work and Occupations, Vol. 24, No. 1, 1997, pp. 56-79.

[44] C. L. Haworth and P. E. Levy, "The Importance of Instrumentality Beliefs in the Prediction of Organizational Citizenship Behaviors," Journal of Vocational Behavior, Vol. 59, No. 1, 2001, pp. 64-75.

[45] D. J. Koys, "The Effects of Employee Satisfaction, Organizational Citizenship Behavior, and Turnover on Organizational Effectiveness: A Unit-Level, Longitudinal Study," Personnel Psychology, Vol. 54, 2001, pp. 101-114.

[46] H. R. Yen and B. P. Niehoff, "Relationship between Organizational Citizenship Behaviors, Efficiency, and Customer Service Perceptions in Taiwanese Banks," Journal of Applied Social Psychology, Vol. 34, No. 8, 2002, pp. 1617-1637.

[47] J. A. LePine, A. Erez and D. E. Johnson, "The Nature and Dimensionality of Organizational Citizenship Behavior: A Critical Review and Meta-Analysis," Journal of Applied Psychology, Vol. 87, No. 1, 2002, pp. 52-65. 